\title{
A century of ice retreat on Kilimanjaro: the mapping reloaded
}

\author{
N. J. Cullen ${ }^{1}$, P. Sirguey ${ }^{2}$, T. Mölg ${ }^{3}$, G. Kaser ${ }^{4}$, M. Winkler ${ }^{4}$, and S. J. Fitzsimons ${ }^{1}$ \\ ${ }^{1}$ Department of Geography, University of Otago, Dunedin, New Zealand \\ ${ }^{2}$ School of Surveying, University of Otago, Dunedin, New Zealand \\ ${ }^{3}$ Chair of Climatology, Technische Universität Berlin, Germany \\ ${ }^{4}$ Centre of Climate and Cryosphere, Institute of Meteorology and Geophysics, University of Innsbruck, Austria \\ Correspondence to: N. J. Cullen (njc@ geography.otago.ac.nz)
}

Received: 20 August 2012 - Published in The Cryosphere Discuss.: 1 October 2012

Revised: 17 December 2012 - Accepted: 7 February 2013 - Published: 4 March 2013

\begin{abstract}
A new and consistent time series of glacier retreat on Kilimanjaro over the last century has been established by re-interpreting two historical maps and processing nine satellite images, which removes uncertainty about the location and extent of past and present ice bodies. Three-dimensional visualization techniques were used in conjunction with aerial and ground-based photography to facilitate the interpretation of ice boundaries over eight epochs between 1912 and 2011. The glaciers have retreated from their former extent of $11.40 \mathrm{~km}^{2}$ in 1912 to $1.76 \mathrm{~km}^{2}$ in 2011 , which represents a total loss of about $85 \%$ of the ice cover over the last $100 \mathrm{yr}$. The total loss of ice cover is in broad agreement with previous estimates, but to further characterize the spatial and temporal variability of glacier retreat a cluster analysis using topographical information (elevation, slope and aspect) was performed to segment the ice cover as observed in 1912, which resulted in three glacier zones being identified. Linear extrapolation of the retreat in each of the three identified glacier assemblages implies the ice cover on the western slopes of Kilimanjaro will be gone before 2020, while the remaining ice bodies on the plateau and southern slopes will most likely disappear by 2040 . It is highly unlikely that any body of ice will be present on Kilimanjaro after 2060 if present-day climatological conditions are maintained. Importantly, the geo-statistical approach developed in this study provides us with an additional tool to characterize the physical processes governing glacier retreat on Kilimanjaro. It remains clear that, to use glacier response to unravel past climatic conditions on Kilimanjaro, the transition from growth to decay of the plateau glaciers must be further resolved, in particular the mechanisms responsible for vertical cliff development.
\end{abstract}

\section{Introduction}

The presence of glaciers in tropical Africa has always been regarded as somewhat of a peculiarity. Johann Rebmann, who is acknowledged as the first European to formally recognize the presence of ice and snow on Kilimanjaro in 1848, referred to Africa's highest mountain as "the mountain whose snows defy the fierceness of the equatorial sun" (Meyer, 1890 , p. 6). Kibo, the highest of three peaks on Kilimanjaro $(5895 \mathrm{~m})$, still harbours ice remnants today, but the recent and well-documented retreat of its glaciers (e.g. Sampson, 1971; Downie and Wilkinson, 1972; Messerli, 1980; Hastenrath, 1984, 2006; Hastenrath and Greischar, 1997; Thompson et al., 2002, 2009; Cullen et al., 2006) provides convincing evidence that present-day climatological conditions are not favourable for glacier growth. To deepen our understanding about past climate conditions that favoured the build-up of ice, it is critical that we establish a consistent record of the changes to the glaciers on Kibo. A detailed knowledge of their behaviour through time allows insight into past climate conditions to be established if the atmospheric processes controlling the observed changes are understood. The glaciers on Kibo, because of their location and exceptional elevation, offer a unique location to sample atmospheric conditions in the tropical mid-troposphere, which is extremely valuable given the influence of low latitude weather and climate processes on global circulation (e.g. Chiang, 2009).

Recent field experiments, complemented with atmospheric and glaciological modelling, have shed new light on the linkages between atmospheric processes across multiple space and time scales and changes to glacier mass on Kilimanjaro (e.g. Mölg and Hardy, 2004; Mölg et al., 2006, 2008a, 
2009a,b, 2012; Cullen et al., 2007; Winkler et al., 2010). It has been carefully demonstrated that the responses of glaciers on Africa's highest mountain are sensitive to both local and large-scale climate dynamics (Mölg and Kaser, 2011), with the former extent of the glaciers providing important insights into past climate conditions (Mölg et al., 2009b). Given the importance of using glacier behaviour to reconstruct climate variability and change, it is critical that we have a consistent and carefully documented record of the changes to the extent of all ice bodies on Kilimanjaro through time.

Since the first detailed observations of Kilimanjaro's glaciers by Hans Meyer in the late 1880s, the dramatic retreat has been described in numerous studies but surprisingly few have included detailed maps of the glaciers. Early assessments that did were dependent primarily on ground-based observations and terrestrial photogrammetry (e.g. Meyer, 1891, 1900; Jaeger, 1909; Klute, 1914, 1920, 1921; Downie et al., 1956; Humphries, 1959). More recently, remote sensing techniques using both aerial photography and satellite imagery have become the method of choice to characterize the ongoing retreat (Hastenrath and Greischar, 1997; Thompson et al., 2002, 2009; Cullen et al., 2006). Beyond the apparent ease of using this approach lies the difficulty of interpreting ice bodies over rugged and steep terrain using remote sensing imagery that is often compromised by snow cover, which leads to the common problem of establishing boundaries between snow and ice. The problem is further complicated by the expectation that ice boundaries determined from new imagery will fit within previously published maps. If one complies with this expectation in an effort to create an updated time series of ice retreat that is consistent with previous work, then it is likely that errors associated with disputable interpretation of ice bodies and/or inaccurate positioning of source imagery in the past will appear in any new interpretation.

To avoid this we have revisited the entire time series of ice retreat, starting with an alternative interpretation of the 1912 photogrammetric survey of Klute (1920) and, later, the ground and aerial observations used by Downie and Wilkinson (1972). In addition, nine satellite images from 1975 to 2011 have been orthorectified in a consistent fashion, providing us with a robust platform from which to establish a more reliable time series of ice retreat. The use of threedimensional (3-D) visualization techniques enhanced and facilitated the interpretation of ice boundaries and allowed us to correct errors that have appeared in previous mapping efforts. Importantly, this study goes beyond clarifying some of the existing disputes about the location and extent of the remaining ice bodies on Kibo by presenting the retreat rates of three different glacier zones, which are segmented using topographical information. This geo-statistical approach further demonstrates the importance of different glacier regimes on Kibo, which have been used successfully as a framework to characterize the different physical processes controlling glacier growth and/or decay on Africa's highest mountain (e.g. Nilsson, 1931; Geilinger, 1936; Kaser et al., 2004, 2010; Cullen et al., 2006; Mölg et al., 2009b).

\section{Data and methods}

\subsection{Historical maps}

\subsubsection{The 1912 survey}

A detailed ground-based photogrammetric survey of Kilimanjaro was conducted in 1912 by Fritz Klute and Eduard Oehler, which in conjunction with information from previous sketches and mapping efforts (e.g. Meyer, 1900; Jaeger, 1909) led to a $1: 50000$ scale map being produced, based on a modified Clark 1880 ellipsoid datum (Klute, 1920, 1921). A scanned version of this product was registered in ESRI ArcGIS software using four intersections of the geographical grid shown on the map using a linear transformation to avoid introducing unwanted distortions. The registered map was then re-projected onto UTM zone 37 South based on the WGS84 ellipsoid (UTM37S), which is the cartographic system we have chosen to use in this study. While the quality of the map should be praised given the complexity of the terrain and the technical limitations of the emerging surveying technique used, severe planimetric distortions were evident and prevented the immediate mapping of the glaciers.

We took advantage of the $50 \mathrm{~m}$ contour lines on the Klute (1920) map to develop an empirical correction for the observed planimetric distortions. This was achieved by creating equivalent $50-\mathrm{m}$ contour lines using a digital elevation model (DEM) sourced from Shuttle Radar Topography Mission (SRTM) data processed and distributed by CGIAR-CSI (Jarvis et al., 2008), which has a 3 arcsecond resolution $(90 \mathrm{~m}$ spatial resolution) (Farr et al., 2007). The SRTM DEM was projected (UTM 37S) to a $30 \mathrm{~m}$ pixel size using a bicubic interpolation. The geolocation accuracy of SRTM DEM, reported to be better than $13 \mathrm{~m}$ (Farr et al., 2007), provided a strong basis for supporting the geometric correction of the historical map. A total of 201 tie points were defined to match contour lines drawn on the historical map to those derived from the SRTM DEM. This process was further supported through the use of a hill-shaded DEM developed to help reveal geomorphological clues and features that facilitated a consistent registration of the map with the underlying terrain. A detailed map produced by Jaeger (1909, map dated 1906) of the glaciers in the western region of Kibo also proved valuable in interpreting the ice boundaries established by Klute (1920).

\subsubsection{The 1953 and 1957 geological surveys}

The University of Sheffield conducted geological surveys of the upper slopes of Kilimanjaro at the invitation of the Tanganyika Geological Survey in 1953 and 1957, which 
resulted in numerous descriptive observations of the glaciers (e.g. Humphries, 1959, Downie, 1964; Downie and Wilkinson, 1972). Humphries (1959) indicated that in 1953 a photogrammetry survey was completed that covered the southwestern slopes of Kibo. Downie and Wilkinson (1972, p. 1) also reported that the whole area could not be visited on the first expedition, and the survey of the glaciers was completed in 1957. Nevertheless, after the first expedition Downie et al. (1956) produced a map of the Kibo caldera showing the basic extent of the ice bodies in this area. Their efforts culminated in the production of the 1963 geological map sheet $56 / 2(1: 50000)$, which depicts the full extent of the ice bodies on Kibo as of February 1962 based on their field observations and aerial photography (Downie and Wilkinson, 1972). Humphries (1972, p. 53) also provided a detailed sketch of the glacier remnants on the western slope of Kibo. Hastenrath and Greischar (1997) report that they mapped the ice extent in 1953 from a 1:25000 scale map produced by Humphries (1953). Efforts to obtain a copy of the 1953 map associated with the unpublished report by Humphries (1953) proved unsuccessful, which led to our decision to use the insert of the 1963 geological map instead. The glacier boundaries as depicted in the insert are representative of the ice extent on Kibo at the end of February 1962. Five intersections of the geographical grid were used to register the map using a linear transformation. Though it is not clearly described, the insert of the 1963 geological map appears to be drawn onto a modified Clark 1880 ellipsoid, which is consistent with the Arc 1960 geodetic datum used in Tanzania. A re-projection to UTM37S/WGS84 allowed the 1963 map to be incorporated into the consolidated GIS created for this study.

\subsection{Satellite data}

\subsubsection{Very high resolution sensors}

The $0.6 \mathrm{~m}$ spatial resolution pan-sharpened and orthorectified QuickBird image described by Cullen et al. (2006), obtained on 1 February 2003, provided the basis for the geolocation of imagery used in this study, as well as being retained to map the areal extent of the glaciers. A Kompsat image from 17 June 2011 was obtained at a L1A processing level to enable a precise orthorectification. Fusion of the four 4-m resolution multi-spectral bands with the 1-m resolution panchromatic band prior to the orthorectification dramatically improved the potential to interpret spatial details in the Kompsat image. Ten ground check points (GCPs) and 12 independent check points (CPs) were collected from the QuickBird image, and elevation data were retrieved from the SRTM DEM to support the orthorectification. The latter was conducted using the sensor model and rational polynomial coefficients supplied by the image provider in ERDAS Imagine 2011, in conjunction with the SRTM DEM, and yielded a root mean square error (RMSE) of $2.5 \mathrm{~m}$ and $2.8 \mathrm{~m}$ for the GCPs and CPs, respectively.

\subsubsection{Advanced Spaceborne Thermal Emission and Reflection Radiometer (ASTER)}

A search through the ASTER archive led to an image from 19 August 2004 being identified as suitable to independently assess and support the orthorectification of other images. A $15 \mathrm{~m}$ DEM was produced following a stereo triangulation of the ASTER bands 3N and 3B in Leica Photogrammetry Suite. Twenty-one tie points and seven GCPs collected from the orthorectified QuickBird image, as well as elevation data from the SRTM DEM, were used and yielded a RMSE of 8.1, 4.4 and $9.3 \mathrm{~m}$ in the easting, northing and elevation directions, respectively. A hill-shaded DEM was then created and compared to that derived from the SRTM DEM. This revealed no noticeable planimetric bias, and demonstrated that the rectification of the ASTER image is consistent with the geolocation accuracy of SRTM data. Importantly, the corresponding orthorectified ASTER image provided an absolute reference (within about $\pm 10 \mathrm{~m}$ ) to assess the rectification of all other images. Furthermore, the almost snow-free ASTER image was extremely useful in our efforts to establish the ice boundaries in the QuickBird and Kompsat images despite its relatively coarse pixel size (i.e. $15 \mathrm{~m}$ ), particularly in the Breach Wall region due to the advantageous illumination and spectral resolution of the sensor. The ASTER image was not used as an epoch in the new time series presented in this study because of its temporal proximity to the QuickBird image.

\subsubsection{Landsat images}

The full archive of Landsat satellite imagery from the Kilimanjaro region available at the Earth Resources Observation and Science (EROS) Center was examined, which led to four epochs being identified as suitable for mapping the remaining ice cover (Table 1). A Landsat 2 Multispectral Scanner System (MSS) image from 15 August 1975 was preferred to that of 24 January 1976 used by Hastenrath and Greischar (1997) as it exhibited much less transient snow. Two Landsat 5 Thematic Mapper (TM) images acquired only a month apart on 24 June and 26 July 1984 were used as they jointly provided a virtually snow free acquisition (the first date was retained as the epoch of reference) with improved spatial resolution (i.e. $30 \mathrm{~m}$ ). The Landsat 4 TM image of November 1989 cited by Hastenrath and Greischar (1997) (no date provided) could not be found in the archive and was therefore not used. Instead, an image from 31 December 1992 was utilised. Finally, a Landsat 7 ETM+ image from 21 February 2000 was obtained to provide an independent assessment of the mapping epoch characterized by Thompson et al. (2002) using an aerial survey. An image fusion technique was also completed to take advantage of the enhanced spatial resolution of the panchromatic band of the ETM+ sensor (i.e. $15 \mathrm{~m}$ ).

The selected Landsat images were orthorectified with the sensor model in ERDAS Imagine using GCPs identified in 
Table 1. Details of the terrestrial photogrammetry and satellite products used to characterize the retreat of the glaciers on Kibo. The spatial resolution is given as either a map scale or pixel size. The number of ground check points (GCPs) used for image matching and the root mean square error (RMSE) $(\mathrm{m})$ associated with the orthorectification $(\mathrm{m})$ are also provided. Two further Landsat images and one ASTER image were also processed but are not listed as they were not formally used for the time series (see Sect. 2.2).

\begin{tabular}{|c|c|c|c|c|}
\hline Map year & Source & Description of the product & $\begin{array}{l}\text { Pixel size } \\
\text { (m) or } \\
\text { map scale }\end{array}$ & $\begin{array}{l}\text { GCP/ } \\
\text { RMSE }\end{array}$ \\
\hline May-Oct 1912 & Klute $(1920,1921)$ & $\begin{array}{l}\text { Terrestrial photogrammetry with } 74 \\
\text { stand-lines, over } 2000 \text { measured points } \\
\text { and additional field sketches }\end{array}$ & $1: 50000$ & - \\
\hline Feb 1962 & $\begin{array}{l}\text { Downie and } \\
\text { Wilkinson (1972) }\end{array}$ & $\begin{array}{l}\text { Terrestrial photogrammetry of western } \\
\text { glaciers, ground observations and aerial } \\
\text { photography }\end{array}$ & $1: 50000$ & - \\
\hline 15 Aug 1975 & Landsat 2 (MSS) & Satellite imagery & 57 & $10 / 59.7$ \\
\hline 24 Jun 1984 & Landsat 5 (TM) & Satellite imagery & 30 & $10 / 10.5$ \\
\hline 31 Dec 1992 & Landsat 4 (TM) & Satellite imagery & 30 & $11 / 8.1$ \\
\hline 21 Feb 2000 & Landsat 7 (TM) & Satellite imagery & 15 & $11 / 6.8$ \\
\hline 1 Feb 2003 & QuickBird $^{\mathrm{a}}$ & Satellite imagery & 0.6 & $-/ 2.6^{\mathrm{b}}$ \\
\hline 17 Jun 2011 & Kompsat $^{\mathrm{a}}$ & Satellite imagery & 1 & $10 / 2.5$ \\
\hline
\end{tabular}

${ }^{a}$ Pan-sharpened multi-spectral imagery.

b Ortho $1: 5000$ product level.

the ASTER image, which had already had its absolute accuracy assessed. MSS and TM/ETM+ images were resampled to 20 and $10 \mathrm{~m}$, respectively, using a bicubic interpolation to facilitate the visual interpretation of the identified ice boundaries. The number of GCPs used and the corresponding RMSE for each image are provided in Table 1. Finally, the co-registration between the orthorectified images was scrutinized and revealed extremely good agreement. Minor distortions were identified in the QuickBird image in the steep south-east region of Kibo, which required a local geometric correction using an empirical rational function model and GCPs collected from the orthorectified Kompsat image. We suspect the source of these distortions may have been from the use of incorrect elevation data in voids from the SRTM DEM used by the image providers during the initial orthorectification process. It is also likely that unfavourable acquisition geometry in conjunction with the steep terrain in this region may have adversely affected the rectification. Following the correction, the ice boundaries for 2003 defined by Cullen et al. (2006) were revised, which resulted in a minor change in the total areal extent.

\subsection{Mapping ice boundaries}

\subsubsection{Previous mapping efforts}

The maps created by Hastenrath and Greischar (1997, Fig. 4) and Thompson et al. (2009, Fig. S2) (referred to in the following as HG97F4 and T09FS2, respectively) were digitized to help facilitate a comparison to the ice boundaries identified in this study. The single geographical coordinate indicated on HG97F4 (i.e. $3^{\circ} 05^{\prime} \mathrm{S}, 37^{\circ} 20^{\prime} \mathrm{E}$ according to a
Clark 1880 ellipsoid) made it difficult to perform a rigorous registration, and raises the question as to whether glacier boundaries in HG97F4 are suitable for reproduction. Instead, links were created to match contour lines with those derived from the SRTM data using a linear transformation to avoid unwanted distortions. The same process of matching contours was used to register T09FS2, which revealed a perfect match with HG97F4. This enabled us to confirm that the glacier outlines prior to 2000 in T09FS2 are a reproduction and edited version of HG97F4, which is also acknowledged by Thompson et al. (2002, 2009). Once both maps were registered in a consistent cartographic system, the glacier boundaries at each epoch (i.e. 1912, 1953, 1976, and 1989 for HG97F4 and T09FS2; 2000 and 2007 for T09FS2) were carefully digitized. This process revealed numerous inconsistencies between the glacier boundaries of HG97F4 and T09FS2. Hastenrath (2006, p. 2) also alluded to a "mapping error" related to the 2000 ice boundaries created by Thompson et al. (2002). To ensure the latter fitted within his own 1989 epoch, Hastenrath (2006) was required to make adjustments to the ice boundaries of the northern ice field. Cullen et al. (2006, Fig. 1) were also required to use an "approximate glacier extent in 1912" as they found it difficult to place some ice remnants observed in 2003 within previously established outlines (e.g. Hastenrath and Greischar, 1997; Thompson et al., 2002), which was scrutinized by Thompson et al. (2009, Fig. S4). These problems prompted us to make the decision to revisit the entire sequence of historical maps and satellite imagery. While it is not our intention to focus on all of the mapping inconsistencies we have observed, we do describe some key differences in detail (see Sect. 3.1) in order 
to characterize the physical processes controlling glacier retreat on Kibo.

\subsubsection{Establishing new ice boundaries}

The boundaries of ice bodies were visually interpreted and digitized from the orthorectified satellite images and historical maps. Despite the variability in the spatial and spectral resolution of the data products, as well as having to account for varying amounts of transient snow in the satellite images, the use of the high temporal resolution sequence significantly improved our ability to interpret the location and extent of ice bodies consistently through time. To support and facilitate the interpretation of all data products (Table 1), three-dimensional visualization techniques were extensively used in conjunction with aerial and ground-based photography from others (e.g. Hastenrath, 2008) and our own field expeditions between 2005-2012. The vantage points from which historical photographs were taken were reproduced in the 3-D model of Kilimanjaro, which proved particularly useful when revisiting the glacier outlines mapped by Klute (1920). The use of 3-D visualization also helped us to interpret glacier positions in relation to distinctive geomorphological features (e.g. moraines, rock outcrops), which are described in more detail in the following section. Finally, to help facilitate future efforts all data products from this analysis have been made available on the Global Land Ice Measurements from Space (GLIMS) Glacier Database.

\section{Results and discussion}

\subsection{The mapping reloaded}

The total amount of ice cover on Kilimanjaro on 17 June 2011 was $1.76 \mathrm{~km}^{2}$ (Table 2), with the location of these ice masses shown in Fig. 1. The remaining ice masses are remnants of more extensive glaciers, which were first mapped and given names by Meyer (1900), with the nomenclature still in use despite the character of the ice bodies having changed dramatically over the last century. The majority of the ice cover observed on Kilimanjaro today fails to strictly adhere to any common definition of a glacier, with most entities isolated and stagnant, but following the definition suggested by Racoviteanu et al. (2009) we include any body of ice that is observed after transient snow melts. It is clear from the accounts and photographs of the early explorers that only the principal glaciers were named and that a considerable number of small, stagnant ice masses, in particular in the crater area, were not formally recognized. This is no more evident than in the south-east crater area, where the first explorers accessed the summit region through a number of weaknesses in the ice referred to as notches (e.g. Hans Meyer and Johannes notches), which have been described in detail elsewhere (e.g. Geilinger, 1936; Hastenrath, 1984). Despite this apparent difficulty it is clear that the remaining ice bodies today are remnants of the more extensive glaciers mapped by Klute (1920) using terrestrial photogrammetry (Table 1), with the boundaries established from this effort reflecting the ice cover in 1912 (Fig. 1). Our calculation of the extent of the glaciers on Kilimanjaro at the end of October in 1912 is $11.40 \mathrm{~km}^{2}$ (Table 2), which is $85 \%$ more than what is observed on the mountain today.

The differences between our interpretation of the 1912 map produced by Klute (1920) and that produced by Hastenrath and Greischar (1997) are also shown in Fig. 1. As noted in Sect. 2.3.2, our interpretation of the glacier boundaries was supported by geomorphological evidence observed using 3-D visualization and historical photographs. Importantly, the 3-D model allowed us to carefully identify and locate the most recent moraines. Using these geomorphological features as markers, we were able to determine with a high degree of accuracy the former location of the glaciers. This approach was particularly useful in establishing the past location and extent of the outlet glaciers feeding from the northern ice field (the Credner, Drygalski, and (Great and Little) Penck glaciers), the Uhlig glacier and the two distinct glacier streams located in the western breach area (the Little and Great Barranco glaciers), as well as the four primary southern ice field glaciers (the Heim, Kersten, Decken and Rebmann). The map produced by Jaeger (1909, map dated 1906) was also valuable in allowing us to identify a number of small ice bodies located above both the Little and Great Barranco glaciers (Fig. 1). Our interpretation of the altitudinal extent of the southern ice field glaciers, at about $4600 \mathrm{~m}$ (Fig. 1), is supported by the photographs of Uhlig (1904, Fig. 50, p. 641) and Klute (1920, Fig. 1). It is important to note that both these historical photographs reveal a complexity of the outcropping rock at the lower elevations of the southern ice field glaciers that we have made an attempt to account for (Fig. 1).

Despite a well-documented and photographic account of the historical retreat of Kilimanjaro's glaciers, which has been carefully reviewed by Hastenrath $(1984,2008)$, there have been a number of inconsistences in the interpretation of ice bodies in recent mapping efforts (e.g. Hastenrath and Greischar, 1997; Cullen et al., 2006; Hastenrath, 2006; Thompson et al., 2002, 2009), which require further clarification as they have an impact on our ability to interpret the physical processes controlling the demise of the glaciers on Kibo. To do this one must briefly reflect on the historical observations, starting with those of Hans Meyer, who provided a sketch (Meyer, 1890, p. 345) and a map (Meyer, 1891) that indicates that an ice stream, which is now referred to as the Furtwängler glacier, flowed over the crater rim into the western breach area. Meyer (1891, p. 319) notes, "the ice from the vast caldera falls as a mighty cascade into the great western fissure, where it unites with the accumulations in the fissure itself". Though Hastenrath (1984, p. 78) disputes whether this ice stream (the Furtwängler glacier) was connected to the Little and/or Great Barranco glaciers, other historical 


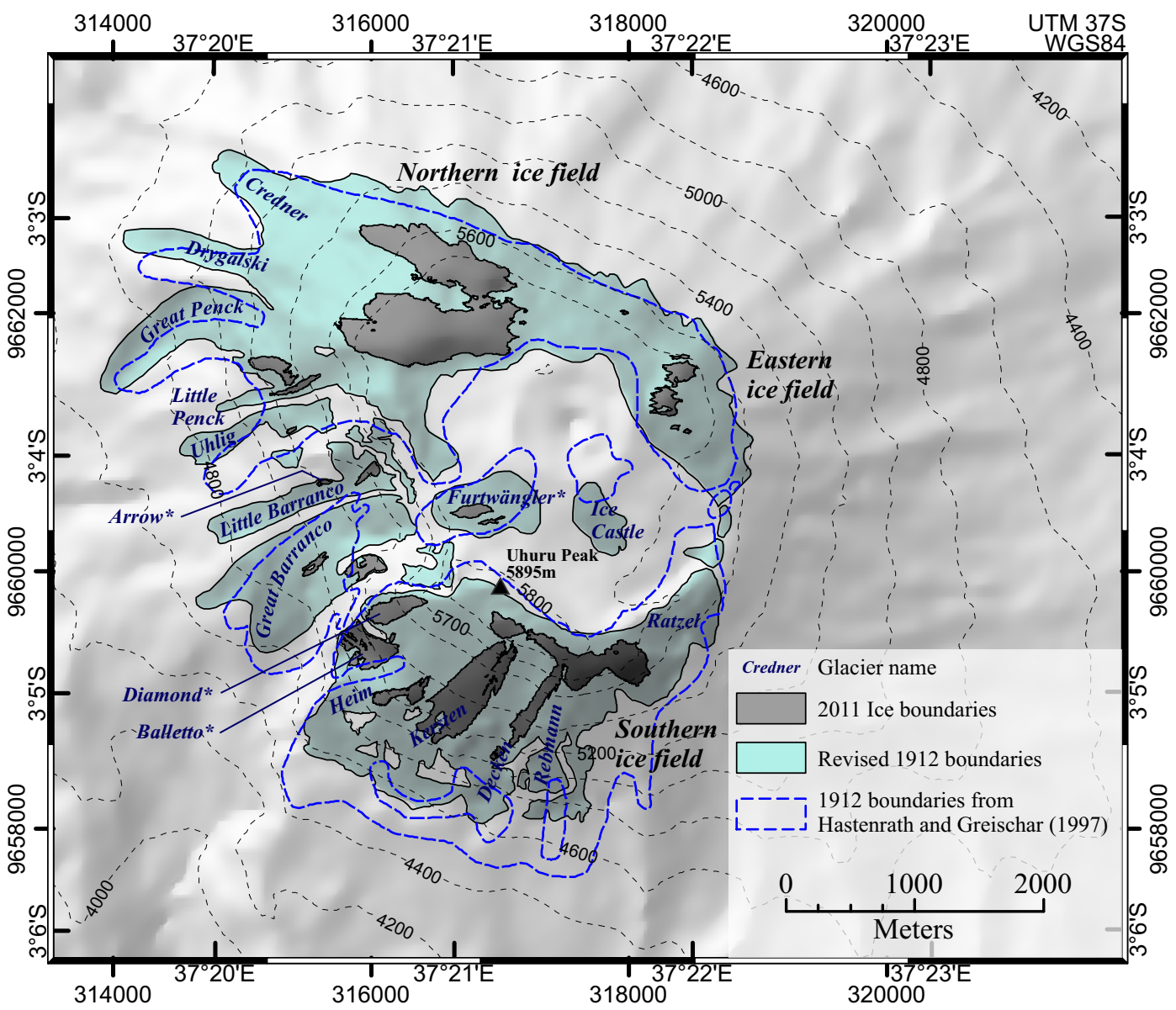

Fig. 1. Glacier extent on Kilimanjaro in 1912 and 2011. Glacier names with an asterisk do not appear in Klute (1920) and are described in the text. The interpretation of the glacier extent for 1912 as defined by Hastenrath and Greischar (1997) is shown as a dashed line (blue) for comparative purposes. The nomenclature for each glacier used by Klute (1920) is given, while the names of four glaciers introduced after this time are indicated using *.

accounts are more supportive (Gillman, 1923; Geilinger, 1936). A more detailed map of Kilimanjaro's glaciers produced by Meyer (1900), based on his observations during a field expedition in 1898, shows the connection no longer existed, suggesting a break-up occurred sometime in the early 1890s. Though the timing is uncertain, the implications of losing this connection are not overlooked by Geilinger (1936, p. 12), who refers to the Little and Great Barranco glaciers as "independent dead glaciers" and made the astute observation that both ice entities were retreating at their upper and lower margins.

This observation holds some importance, as it helps clarify the source of the ice remnants still observed today. The maps by Meyer (1900, map dated 1898), Jaeger (1909, map dated 1906) and Klute (1920, map dated 1912) clearly show distinct ice streams for the Little and Great Barranco glaciers, which as noted may have been fed by ice from the Furtwängler glacier as recently as the late 19th century. Our revision of the Klute (1920) map from 1912 (Fig. 1) honours the discrete boundary between the Little and Great Barranco glaciers, which is not as clearly depicted in the Hastenrath and Greischar (1997) interpretation. The failure to clearly distinguish the boundaries and location of these two independent ice streams has been inherited by Thompson et al. (2002, 2009), who used the Hastenrath and Greischar (1997) interpretation of the ice extent prior to 2000 (see Sect. 2.3.1). Thompson et al. (2009) argue that ice remnants identified by Cullen et al. (2006) in both the ice streams of the former and more extensive Little and Great Barranco glaciers are absent from previous observations and therefore most likely transient snow. The sketch by Humphries (1972, Fig. 4.6) and the map produced by Messerli (1980, Fig. 6) also support the interpretation by Cullen et al. (2006), while the ice bodies in question have been identified in each of the satellite images used in the present analysis (Fig. 2). Though not labelled by Humphries $(1959,1972)$ or by those preceding his observations, the Arrow glacier has been used to refer to one of the Little Barranco ice remnants (Fig. 1). It appears that this term was adopted by climbers on the mountain (e.g. Sampson, 1971, p. 202), but the exact location of this ice body is 
Table 2. Areal extents $\left(\mathrm{km}^{2}\right)$ of the total ice bodies between 1912 and 2011 , as well as for zone 1 (western region), zone 2 (plateau region) and zone 3 (southern region) as defined in the text and Fig. 4. The annual rates of area change per observation period $\left(10^{-2} \mathrm{~km}^{2} \mathrm{yr}^{-1}\right) \operatorname{are}^{-}$ shown in parentheses for the total and zoned areas.

\begin{tabular}{|c|c|c|c|c|c|c|c|c|c|}
\hline \multirow[t]{2}{*}{ Epoch } & \multirow{2}{*}{$\begin{array}{r}\text { Duration } \\
\text { [years] }\end{array}$} & \multicolumn{8}{|c|}{ Area $\left[\mathrm{km}^{2}\right]\left(\right.$ rate of area change $\left.\left[10^{-2} \mathrm{~km}^{2} \mathrm{yr}^{-1}\right]\right)$} \\
\hline & & \multicolumn{2}{|c|}{ Total } & \multicolumn{2}{|c|}{ Zone 1} & \multicolumn{2}{|c|}{ Zone 2} & \multicolumn{2}{|c|}{ Zone 3} \\
\hline 1912.83 & & 11.400 & & 4.540 & & 4.293 & & 2.567 & \\
\hline 1962.16 & 49.36 & 7.320 & $(-8.27)$ & 2.520 & $(-4.09)$ & 3.161 & $(-2.29)$ & 1.639 & $(-1.88)$ \\
\hline 1975.62 & 13.47 & 6.052 & $(-9.41)$ & 2.060 & $(-3.42)$ & 2.529 & $(-4.69)$ & 1.463 & $(-1.31)$ \\
\hline 1984.48 & 8.87 & 4.815 & $(-13.95)$ & 1.628 & $(-4.87)$ & 1.949 & $(-6.54)$ & 1.238 & $(-2.54)$ \\
\hline 1993.00 & 8.53 & 3.800 & $(-11.90)$ & 1.142 & $(-5.70)$ & 1.638 & $(-3.65)$ & 1.020 & $(-2.56)$ \\
\hline 2000.14 & 7.15 & 2.920 & $(-12.32)$ & 0.701 & $(-6.17)$ & 1.411 & $(-3.18)$ & 0.808 & $(-2.97)$ \\
\hline 2003.08 & 2.95 & 2.500 & $(-14.25)$ & 0.539 & $(-5.50)$ & 1.251 & $(-5.43)$ & 0.710 & $(-3.32)$ \\
\hline 2011.46 & 8.38 & 1.762 & $(-8.81)$ & 0.333 & $(-2.46)$ & 0.937 & $(-3.75)$ & 0.492 & $(-2.60)$ \\
\hline
\end{tabular}

not well documented and we are uncertain that the remnant identified in Fig. 1 and by Cullen et al. (2006) is the same as that referred to by others (e.g. Sampson, 1971; Messerli, 1980; Hastenrath and Greischar, 1997).

There has also been some confusion about the Diamond and Balletto glaciers (Fig. 1), which were not formally recognized in the early mapping work (Meyer, 1990; Jaeger, 1909; Klute, 1920), or acknowledged by Humphries (1959, 1972) but are both described by Hastenrath (1984), while Sampson (1971) and Messerli (1980) only refer to the former. The Breach Wall area, where both glaciers are located, was mapped by Klute (1920), but as no break up from the southern ice field had occurred at this time they were not given discrete labels (Fig. 1). However, what is indisputable is the presence of an ice field (the Balletto glacier) beneath the headwall of the Diamond glacier, which was not mapped by Thompson et al. $(2002,2009)$. The presence of this ice field is not only observed in the satellite record but is documented by Reinhold Messner (Messner, 1991, Chapter 21), who made the first (and only) direct ascent of the Breach Wall of Kilimanjaro in 1978. Though Cullen et al. (2006) mapped this region of ice (the Balletto glacier), they failed to label it correctly, placing the label beneath the Heim glacier after following the interpretation of Hastenrath and Greischar (1997, Fig. 2). Further, the Diamond glacier is absent after 1976 in the maps produced by Hastenrath and Greischar (1997) and Hastenrath (2006), but appears in the Thompson et al. (2002, 2009) maps despite using the former to build their time series. Finally, the Uhlig glacier, which Jaeger (1909, p. 130) named after his friend $\mathrm{C}$. Uhlig, does not appear to have been connected to the northern ice field in the past (Fig. 1). While the upper boundary of the Uhlig glacier is difficult to interpret in the Klute (1920) map, it is clearly shown by Jaeger (1909) that it was not joined to the northern ice field.

Figure 2 shows the change in ice extent over almost a 100yr period, which is consistent through time and removes most of the uncertainty about the location and extent of the remaining ice bodies on Kibo. The retreat over the first part of the 20th century was approximately $4.1 \mathrm{~km}^{2}$ (Fig. $2 \mathrm{a}$ and b), while over the last $50 \mathrm{yr} 5.6 \mathrm{~km}^{2}$ of the ice cover has been lost (Fig. 2c-h). The retreat between 1912 and 1962 (Fig. 2a and b) resulted in a distinct break-up of ice in the vicinity of the notches (south-east crater region), separating the northern and eastern ice fields from the southern ice field. Remnants of the Ice Castle (Fig. 1) still remained in 1962, and were described by Sampson (1971) as still being present in the early 1970s but appeared to have been lost by 1975 (Fig. 2c). Other noticeable features of the retreat in the early 20th century include the development of a distinct separation between the Great and Little Penck glaciers, which formed through the expansion of the Ravenstein (first mapped by Meyer, 1900), the rapid demise of the Uhlig glacier and the split-up of the Diamond and Balletto glaciers from the southern ice field (Fig. 2a and b).

Between 1962 and 1975 the persistent retreat of ice led to the northern and eastern ice fields becoming separated from each other, as did the Great Penck glacier from the northern ice field (Fig. $2 b$ and c). The Little Penck proved more resistant and did not separate from the northern ice field until after 1992, while the remnant of the Great Penck completely disappeared during this period (Fig. 2e and f), though ground-based (field) observations in January 2005 revealed debris-covered ice at the location of the lowest 1984 extent (Fig. 2d). As noted by others (e.g. Hastenrath and Greischar, 1997; Cullen et al., 2006) the northern ice field developed a hole sometime after 1984 (Fig. 2d and e), which opened into a large canyon after 2003 (Fig. $2 \mathrm{~g}$ and h). Field observations by the first author in October 2012 revealed that the northern ice field has separated into two independent ice bodies, which must have occurred sometime after 17 June 2011. The Furtwängler glacier has also separated into smaller ice entities, which began after 2003 (Fig. $2 \mathrm{~g}$ and h). The southern ice field has not escaped the on-going demise, with the upper part of the Kersten glacier separating from its lower reaches between 2003 and 2011 (Fig. 2g and h), which was somewhat anticipated after mass balance modelling showed this 


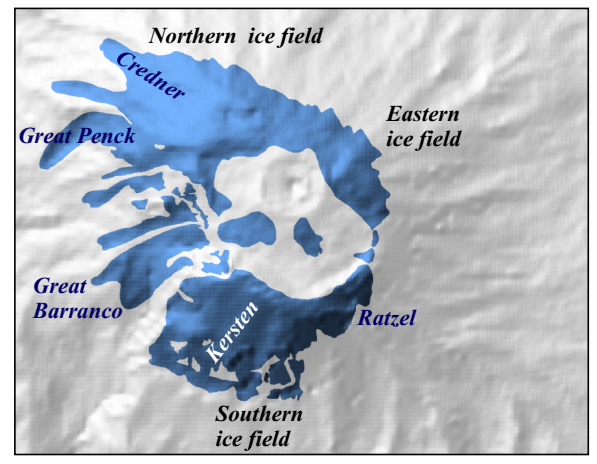

(a) 1912

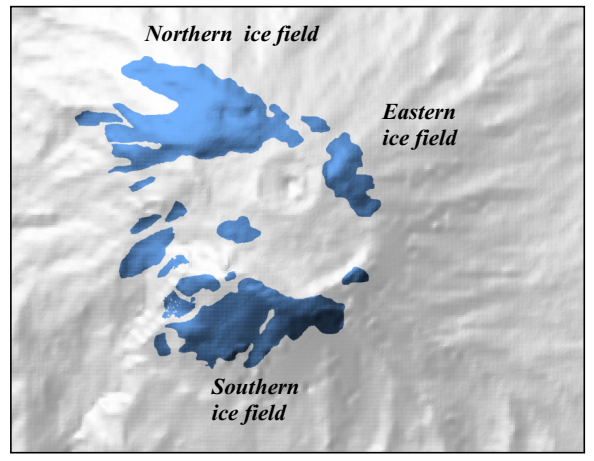

(c) 1975

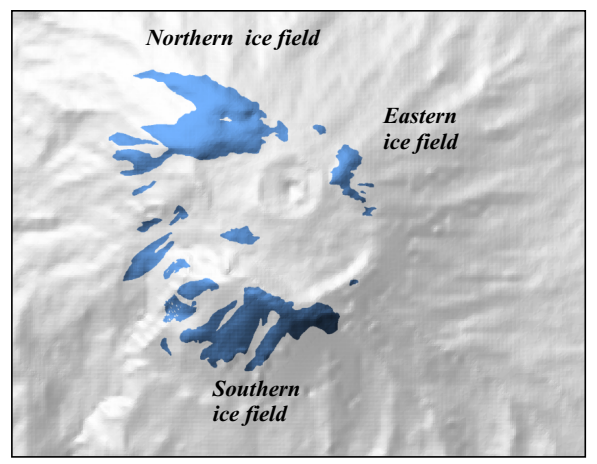

(e) 1992

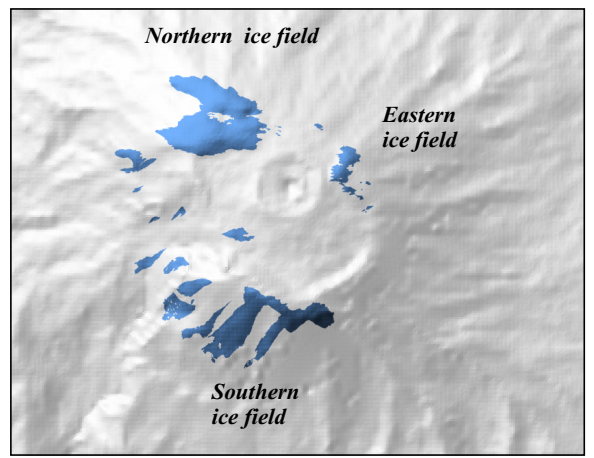

(g) 2003

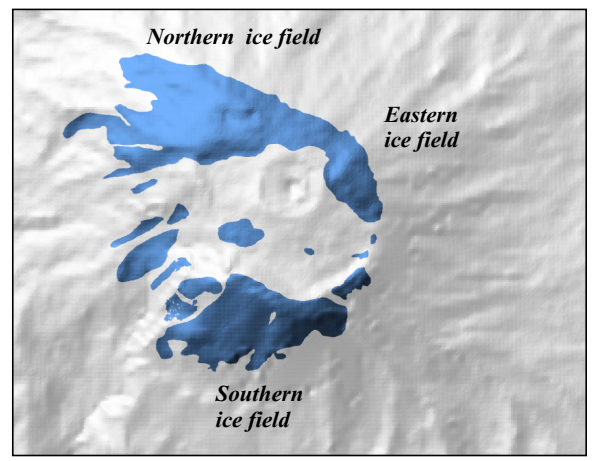

(b) 1962

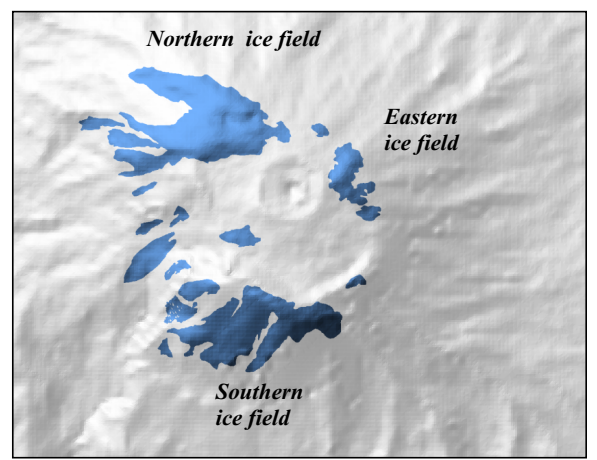

(d) 1984

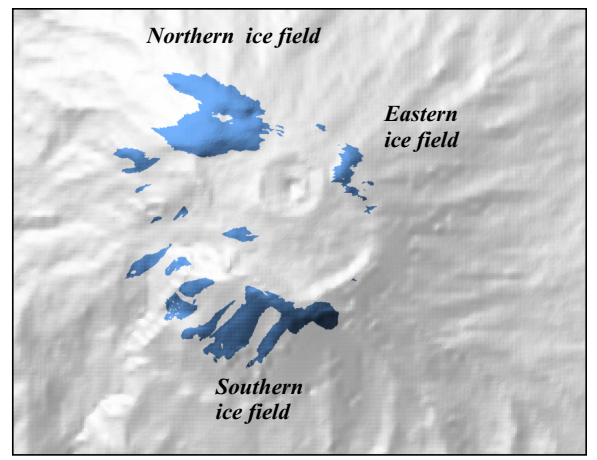

(f) 2000

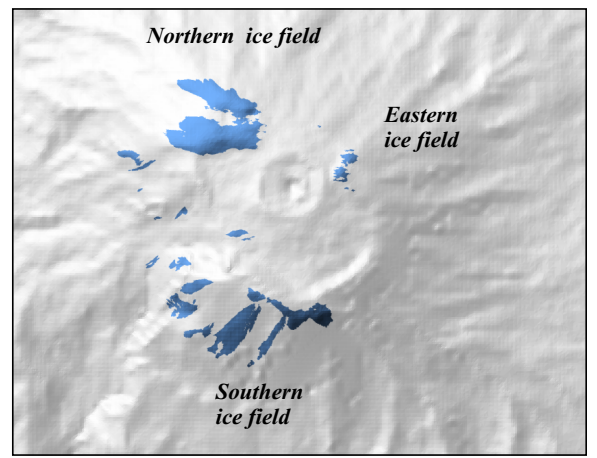

(h) 2011

Fig. 2. Ice retreat over Kilimanjaro based on the revised areal extent for the following years: (a) 1912, (b) 1962, (c) 1975, (d) 1984, (e) 1992, (f) 2000, (g) 2003, and (h) 2011. An interactive 3-D illustration of the sequence can be sourced in the Supplement. 
was likely to occur (Mölg et al., 2009b). The upper part of the Heim has disappeared and the Decken has narrowed considerably over the last $8 \mathrm{yr}$ (Fig. $2 \mathrm{~g}$ and h).

\subsection{New interpretation of the ice retreat}

A consistent record of the former extent of the glaciers on Kibo provides a platform from which the relationship between glaciological and meteorological processes can be further explored. We believe the spatial and temporal variability of the ice cover on Kibo can be used to unravel the physical processes responsible for controlling the decay of the ice masses through time, as well as providing insights into the mechanisms that may have been responsible for growth in the past. Interestingly, those who were privileged to make some of the first (formal) observations on Kilimanjaro recognized there was an asymmetry in the ice cover (e.g. Meyer, 1891), which pointed to specific climatological drivers controlling glacial retreat (e.g. Gillman, 1923; Nilsson, 1931; Geilinger, 1936). Meyer (1891, p. 308-314) noted that "an immense mountain mass like Kilimanjaro must considerably modify the prevailing wind direction" before making the point that the primary cause in the variability of the ice limit is "the unequal distribution of moisture on the northern and southern sides of the mountain". Though Meyer (1891) recognized variability in moisture was the most important control, he also speculated that the asymmetry of low reaching glaciers on Kibo in the south, south-west and western sectors of the mountain, a pattern that persisted throughout the 20th century (Fig. 2), depended on "local peculiarities which favour the preservation of the snow [rather] than on physical conditions that favour a large snowfall" (Meyer, 1891, p. 315). To revisit this early observation, it is useful to reflect on the hypsometry of the glaciers in 1912 (Fig. 3a), which shows that the probability density in relation to the distribution of the ice was greatest above $5700 \mathrm{~m}$. This high density reflects the ice cover in the crater region, with the majority of the ice in 1912 being part of the former ice cap that linked the northern and eastern ice fields (Fig. 1). Figure $3 \mathrm{~b}$ and $\mathrm{c}$ show that slope and aspect were also important controls on the density of ice cover, with the steep south and south-west facing slopes more favourable, which enabled the glaciers to extend to elevations below $4600 \mathrm{~m}$. For the glaciers to have extended to the same elevation on the east-facing slopes, they would have had to cover a much greater horizontal distance (Fig. 1).

To fully account for the distinct geometry of the ice masses on Kibo, and to establish the physical processes controlling their location and extent through time, Kaser et al. (2004) established a framework that included four separate glacier regimes. The motivation to do this was partly based on the early recognition that the tabular shaped glaciers in the crater region of Kibo behave differently to glaciers on the flanks of the mountain (e.g. Nilsson, 1931; Geilinger, 1936). Guided by this distinction Cullen et al. (2006) used the $5700 \mathrm{~m}$ contour, which is roughly the height of the outer crater rim, to
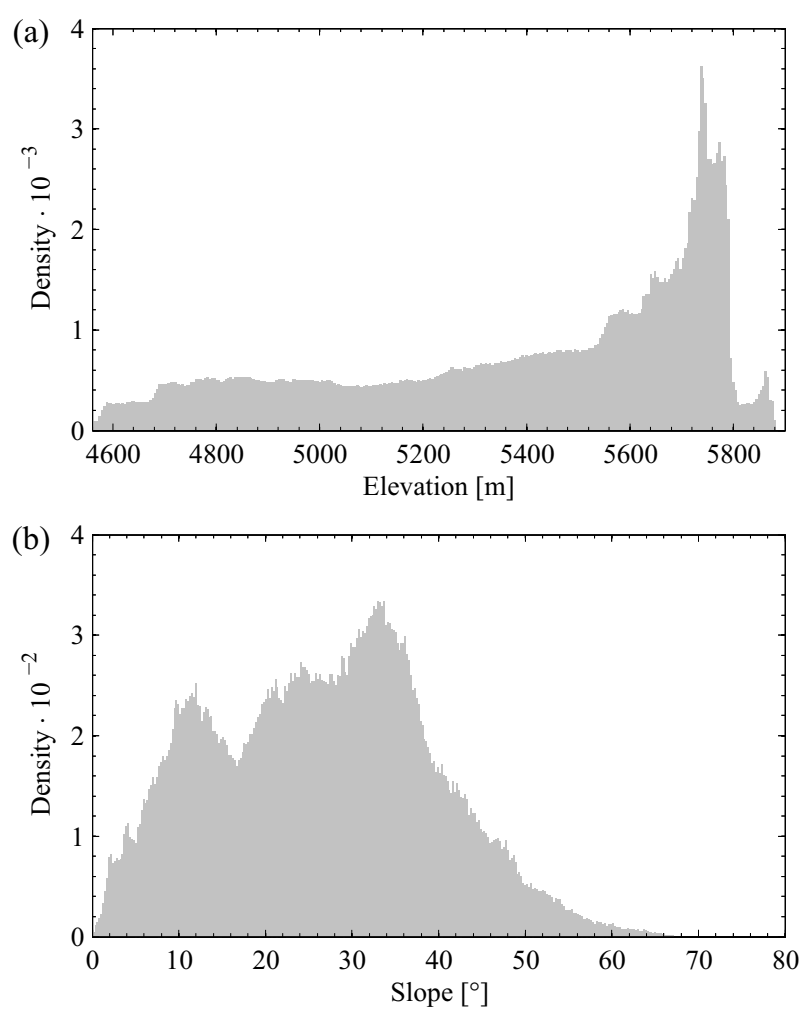

(c)

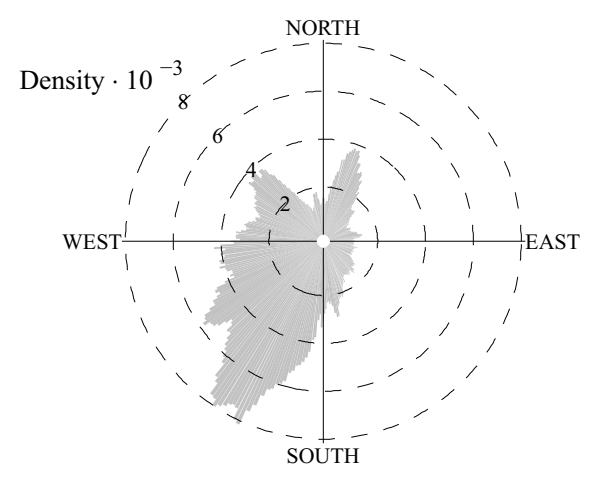

Fig. 3. Distribution of topographic measures from the areal extent of all ice bodies in 1912: (a) elevation, (b) slope, and (c) aspect. The magnitude of the normalised distribution on the $y$-axis is a probability density function, with the integral equal to unity.

distinguish between two broad glacial systems: (1) plateau $(\geq 5700 \mathrm{~m})$ and slope $(<5700 \mathrm{~m})$ glaciers. This simple binary classification has proved useful in describing some of the key physical processes responsible for the retreat of ice on Kibo (e.g. Mölg et al., 2009b; Kaser et al., 2010). To further characterize the spatial and temporal variability of glacier retreat on Kibo, we have adopted a geo-statistical approach in this study that uses elevation, slope and aspect of the ice cover in 1912 (the feature space) to identify clusters resembling topographical classes. This was achieved by performing a cluster analysis containing maximum likelihood estimates of the topographical parameters in a Gaussian 
mixture model (McLachlan and Peel, 2000), which resulted in three broad glacial zones being identified: (1) western region (zone 1), (2) plateau region (zone 2) and (3) southern region (zone 3) (Fig. 4).

Figure 5 shows the rate of retreat of each of the glacial zones through time, as well as a least-squares linear regression fit (and $80 \%$ confidence intervals) through each of the glacial zone time series. As described by Cullen et al. (2006), the retreat of the tabular shaped plateau glaciers (zone 2) is controlled primarily by solar radiation-induced ablation on the vertical cliffs that characterize them, as demonstrated through radiation modelling (Mölg et al., 2003). Winkler et al. (2010) revealed that direct insolation is the reason for the predominant zonal alignment of the ice cliffs and their bimodal annual recession (sunlit versus shaded periods). Though the shrinkage of the ice cover along the vertical cliffs is fairly constant from year to year, the areal retreat of the zone 2 region is not entirely linear, with the highest rates occurring between 1975 and 1984 (Table 2), which correspond to the period following the separation of the northern and eastern ice fields (Fig. 2). Therefore, changes in the geometry of the ice bodies and their exposure to solar radiation appear to have led to variations in retreat rates (Table 2 and Fig. 5), which has also been described by Kaser et al. (2010).

An explanation for the growth and decay of the plateau glaciers, including a description of the physical processes that may have led to the observed steps in the northern ice field, has been provided by Kaser et al. (2010). To sustain growth in the crater rim region (zone 2), it is critical that snowfall is sufficient to allow a continuous snow cover to develop that is able to survive from one year to the next. If the annual build-up of snow is sustained through a period of time, it is quite conceivable that the plateau glaciers could grow to several tens of metres in thickness quite quickly, raising the question as to whether this accumulation of ice has the potential to become a source of mass for glaciers on the western flanks of the mountain (zone 1). Meyer (1891, p. 316-317) was somewhat sceptical as to whether the plateau region acted as a "reservoir" and thought it "much more reasonable to suppose that the rocky rim of the crater is the real reservoir". However, Meyer $(1890,1891)$ did provide an account and sketches to support a connection of the plateau ice to the Little and Great Barranco glaciers in the past, which as described may have been important in sustaining them (Gillman, 1923; Geilinger, 1936). There is some importance in investigating the extent of the linkages between these two glacial zones as together they accounted for almost $80 \%$ of the total ice cover in 1912 (Table 2).

The remaining ice bodies in zone 2 (plateau region) are mostly stagnant today, with field measurements and preliminary modelling results indicating deformation rates of ice within the crater are small $\left(<10 \mathrm{~cm} \mathrm{yr}^{-1}\right)$ (Kaser et al., 2004; Winkler et al., 2010). It seems unlikely that the present or historical thickness of the plateau ice has been sufficient to allow substantial deformation (Kaser et al., 2004), suggesting

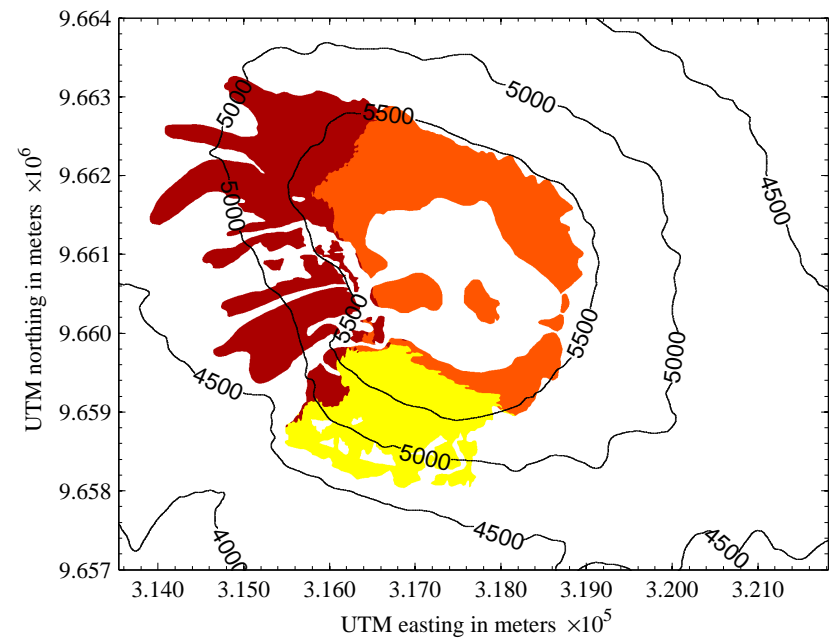

Fig. 4. Classification of regions based on the distribution of topographic measures in 1912. Zone 1 (western region), zone 2 (plateau region) and zone 3 (southern region) are shown in red, orange and yellow, respectively.

that mass transport from the nearly horizontal plateau down into the western slope glaciers (zone 1) has most likely been minor. Careful observations by Klute (1920) demonstrated that the velocity of the centre of the Great Penck glacier was $0.64 \mathrm{~m}$ over a 30-day period in 1912, which led him to speculate that the annual downslope movement was about $7 \mathrm{~m}$ per year. It should be noted that Nilsson (1931) and Osmaston (1989) also report on these observations but incorrectly cite Jaeger (1909) as the person responsible for obtaining the measurements. Nonetheless, it is improbable that ice from the plateau region could have supported the observed flow dynamics of the Great Penck glacier, with the upper reaches of the mountain flanks the most likely source of the mass. Thus, the growth and decay of the glaciers in zone 1 (western region) do not appear to be directly dependent on the stability of plateau ice (zone 2). To further resolve the physical processes controlling the stability of the plateau ice, it would be of interest to develop a better understanding of the mechanisms responsible for vertical cliff development.

The glaciers on the southern slopes (zone 3) differ from those on the western slopes (zone 1) as they are separated from the large masses of ice within the caldera (zone 2) by bed topography (Humphries, 1972). This distinction is important, as any assessment of the atmospheric controls on the behaviour of the southern ice fields is independent of the complexity of the vertical cliff retreat in the plateau region (zone 2). That said, the cluster analysis that led to the topographical classes used in this study shows that the upper sections of the southern ice field exhibit similar physical characteristics to the ice within the caldera (Fig. 4). Nevertheless, to obtain a full solution for the asymmetry of the glaciers on Kibo that the early explorers observed, it is critical to establish an understanding of the atmospheric 


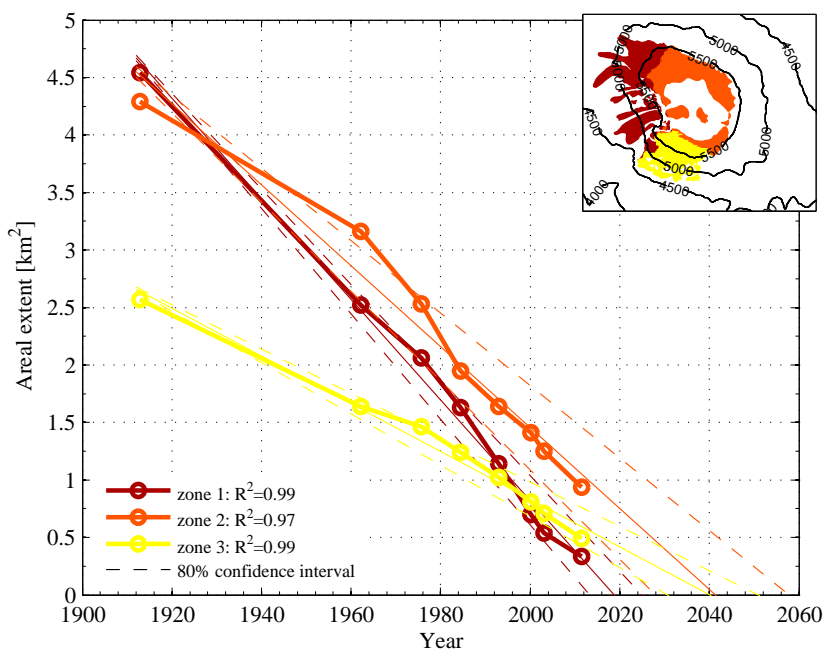

Fig. 5. The areal change of glaciers and ice bodies based on the three-member classification. Linear regressions (thin solid lines) for each of the three zones are shown, as well as the $80 \%$ confidence intervals for each of these relationships.

processes controlling the growth and/or decay of the southern ice fields. This has been achieved by Mölg et al. (2009b), who used observations and atmosphere-glacier modelling to show how critical precipitation, humidity and fractional cloud cover are on the energy and mass balance of the Kersten glacier (zone 3). These results compare favourably to early accounts of the importance of precipitation (moisture change) and cloud cover on the asymmetry (Meyer, 1891; Klute, 1920, Gillman, 1923; Geilinger, 1936), with the diurnal variability of cloud cover being especially important in providing protection to the glaciers on the western side of the mountain (e.g. Meyer, 1891; Hastenrath and Greischar, 1997).

Recent regional atmospheric modelling experiments have provided a more quantitative assessment to account for the asymmetry in glacier mass on Kibo, demonstrating that the west and south-western areas of the mountain are favourable to moisture convergence as controlled by atmospheric dynamics (Mölg et al., 2009a). As noted by Osmaston (1989), the asymmetry is not confined to the most recent glacier extents, with the pattern of ice distribution established from former moraines indicating that recent climatic controls on glacier behaviour are similar to those in the past. This suggests that establishing the specific nature of the atmospheric controls responsible for the most recent shift from glacier growth to decay, in particular in zones 2 and 3 (plateau and southern slope regions), remains critical if we are to use glacier behaviour to reconstruct climatic conditions of the deeper past.

Finally, it is difficult not to speculate on when the ice on Kibo will disappear, which becomes more achievable if one recognizes the importance of the different glacial zones on the mountain. If one accepts linear extrapolation based on changes from the past is suitable to make projections for the future, it is apparent that the ice cover in zone 1 (western region) will most likely be gone before 2020 and that ice in zone 2 (plateau) and zone 3 (southern slopes) will disappear sometime close to 2040 (Fig. 5). It is likely that the plateau will harbour the final remnants of ice on Kibo, which could remain slightly beyond the middle of the 21 st century. Interestingly, our linear extrapolation for the loss of ice is in close agreement to earlier projections using radiation modelling (Mölg et al., 2003). Though the loss of ice will have no hydrological significance to lowland areas (e.g. Gillman, 1923; Kaser et al., 2004; Mölg et al., 2008b), there is no doubt that their disappearance will be a "grievous aesthetic loss" (Salt, 1951 , p. 160), which will undoubtedly impact the experience tourists have on the mountain (Mölg et al., 2008b).

\section{Conclusions}

With reference to the glaciers found on Mt. Kenya and Kibo in East Africa, C. Gillman remarked, "we might perhaps learn a good deal as to the general world circulation from careful and prolonged observation on these particular summits" (Mackinder, 1923, p. 23). This statement still holds true today (e.g. Mölg et al., 2006), and, with the increasing awareness that glaciers on Africa's highest mountain can be used to extract climate information from the past, it seemed timely to revisit the mapping of the ice cover on Kibo through time. Our motivation to do so has been to ensure the historical record of these changes is of the highest possible quality and in a format that should help facilitate on-going and future research dedicated to resolving the complexity of climate variability and change in East Africa and beyond. This was achieved by using a consistent cartographic framework that allows historical maps and new satellite imagery to be examined. The use of three-dimensional visualization techniques greatly enhanced our ability to establish the former location of the glaciers.

The revisited time series of glacial retreat on Kilimanjaro contains eight epochs and spans almost $100 \mathrm{yr}$ (19122011). The glaciers have retreated from their former extent of $11.40 \mathrm{~km}^{2}$ in 1912 to $1.76 \mathrm{~km}^{2}$ in 2011 , which represents a loss of about $85 \%$ of the ice cover over almost a $100-y r$ period. Our estimate of the total retreat is consistent with recent assessments (Cullen et al., 2006; Thompson et al., 2009), but the careful re-examination of the location and extent of individual ice bodies through time has allowed us to identify a number of important differences from previously published maps (e.g. Hastenrath and Greischar, 1997; Thompson et al., 2002, 2009). Historical evidence has been used to support our interpretation, with the detailed observations and photographs obtained by early explorers on Kilimanjaro found to be extremely valuable (e.g. Meyer, 1891, 1900; Uhlig, 1904; Jaeger, 1909; Klute, 1914, 1920, 1921; Gillman, 1923; Nilsson, 1931; Geilinger, 1936). It has to be acknowledged that 
much of what we know about Kilimanjaro today was established through their efforts.

To further explore the importance of different glacier regimes on Kibo (Kaser et al., 2004), a geo-statistical approach was applied, which resulted in the segmentation of the ice cover into three broad glacial zones. A careful examination of the retreat of ice in each of these glacier zones indicates that there is a high probability that most of the remaining ice cover on Kilimanjaro will disappear by 2040 , and it is highly unlikely that any ice body will remain after 2060 if present retreat rates are maintained. Before this happens it would still be useful if the remaining ice bodies, in particular the remnants of the northern ice field, could be further examined to help resolve existing uncertainties about the mechanisms responsible for controlling the formation of the vertical cliffs that characterize them (e.g. Winkler et al., 2010). In addition, further efforts are required to scrutinize the exact timing of the onset of the present glacier retreat first reported by Hans Meyer in the late 19th century. If we can refine our understanding of the atmospheric controls behind the most recent shift from glacier growth to decay on Kibo, we will be in a stronger position to characterize the climatic controls of past and much larger glaciations on Africa's highest mountain.

\section{Supplementary material related to this article is available online at: http://www.the-cryosphere.net/7/419/ 2013/tc-7-419-2013-supplement.pdf.}

Acknowledgements. This research is funded by the Department of Geography and School of Surveying, University of Otago, New Zealand. Thomas Mölg was supported by the Alexander von Humboldt Foundation. The contributions made by Georg Kaser and Michael Winkler were supported by the Austrian Science Fund (FWF) Projects P 20089-N10 and P 21288-N10. This research would not have been possible without the support from the following Tanzanian authorities (COSTECH, KINAPA, TANAPA, TAWIRI). We are grateful to the referees that took the time to provide feedback on this research, in particular the careful and thoughtful comments by Henry Brecher.

Edited by: M. Schneebeli

\section{References}

Chiang, J. C. H.: The tropics in paleoclimate, Annu. Rev. Earth Planet. Sci., 37, 263-297, 2009.

Cullen, N. J., Mölg, T., Kaser, G., Hussein, K., Steffen, K., and Hardy, D. R.: Kilimanjaro Glaciers: Recent areal extent from satellite data and new interpretation of observed 20th century retreat rates, Geophys. Res. Lett., 33, L16502, doi:10.1029/2006GL027084, 2006.
Cullen, N. J., Mölg, T., Kaser, G., Steffen, K., and Hardy, D. R.: Energy-balance model validation on the top of Kilimanjaro, Tanzania, using eddy covariance data, Ann. Glaciol., 46, 227-233, doi:10.3189/172756407782871224, 2007.

Downie, C.: Glaciations of Mount Kilimanjaro, Northeast Tanganyika, Geol. Soc. Am. Bull., 75, 1-16, doi:10.1130/00167606(1964)75[1:GOMKNT]2.0.CO;2, 1964.

Downie, C. and Wilkinson, P.: The Geology of Kilimanjaro, Sheffield: Geology Department, University of Sheffield, 1972.

Downie, C., Humphries, D. W., Wilcockson, W. H., and Wilkinson, P.: Geology of Kilimanjaro, Nature, 178, 828-830, 1956.

Farr, T. G., Rosen, P. A., Caro, E., Crippen, R., Duren, R., Hensley, S., Kobrick, M., Paller, M., Rodriguez, E., Roth, L., Seal, D. Shaffer, S., Shimada, J., Umland, J., Werner, M., Oskin, M., Burbank, D., and Alsdorf, D.: The Shuttle Radar Topography Mission, Rev. Geophys., 45, RG2004, doi:10.1029/2005RG000183, 2007.

Geilinger, W.: The retreat of the Kilimanjaro glaciers, Tanganyika Notes and Records, 2, 7-20, 1936.

Gillman, C.: An ascent of Kilimanjaro, Geogr. J., 61, 1-27, 1923.

Hastenrath, S.: The Glaciers of Equatorial East Africa, Reidel, Dordrecht, 1984.

Hastenrath, S.: Diagnosing the decaying glaciers of equatorial East Africa, Meteorol. Z., 15, 265-271, doi:10.1127/09412948/2006/0106, 2006.

Hastenrath, S.: Recession of equatorial glaciers: a photo documentation, Sundog Publishing, Madison, Wisconsin, 2008.

Hastenrath, S. and Greischar, L.: Glacier recession on Kilimanjaro, East Africa, 1912-89, J. Glaciol., 43, 455-459, 1997.

Humphries, D.: Interim report on the glaciology and meteorology of Kilimanjaro, Tanganyika: July-Sept. 1953, Geological Survey of Tanganyika, Dodoma, 1953.

Humphries, D.: Preliminary notes on the glaciology of Kilimanjaro, J. Glaciol., 3, 475-479, 1959.

Humphries, D.: Glaciology and glacial history, in: The Geology of Kilimanjaro, edited by: Downie, C. and Wilkinson, P., Sheffield, Geology Department, University of Sheffield, 31-71, 1972.

Jarvis, A., Reuter, H. I., Nelson, A., and Guevara, E.: Hole-filled SRTM for the globe Version 4, available from the CGIAR-CSI SRTM 90 m Database (http://srtm.csi.cgiar.org), 2008.

Jaeger, F.: Forschungen in den Hochregionen des Kilimandscharo, Mitt. Deutsch. Schutzgebiet., 22, 113-197, 1909.

Kaser, G., Hardy, D. R., Mölg, T., Bradley, R. S., and Hyera, T. M.: Modern glacier retreat on Kilimanjaro as evidence of climate change: Observations and facts, Int. J. Climatol., 24, 329-339, 2004.

Kaser, G., Mölg, T., Cullen, N. J., Hardy, D. R., and Winkler, M.: Is the decline of ice on Kilimanjaro unprecedented in the Holocene?, Holocene, 20, 1079-1091, doi:10.1177/0959683610369498, 2010.

Klute, F.: Forschungen am Kilimandscharo im Jahre 1912, Geogr. Zeitschrift, 20, 496-505, 1914.

Klute, F.: Ergebnisse der Forschungen am Kilimandscharo 1912, Reimer-Vohsen, Berlin, 1920.

Klute, F.: Die stereophotogrammetrische Aufnahme der Hochregionen des Kilimandscharo, Zeitschrift Ges. Erdkunde Berlin, 56, 144-151, 1921.

Mackinder, C. W., Hobley, C., Gillman, C., and Johnston, H.: An ascent of Kilimanjaro: Discussion, Geogr. J., 61, 1-27, 1923. 
McLachlan, G. and Peel, D.: Finite Mixture Models, John Wiley and Sons, New York, 2000.

Messerli, B.: Mountain glaciers in the Mediterranean area and in Africa, in: Proceedings of the Riederalp Workshop, September 1978, IAHS-AISH Publ. no. 126, 197-211, 1980.

Messner, R.: Free spirit: a climber's life, Hodder and Stoughton, Great Britain, 1991.

Meyer, H.: Ascent to the Summit of Kilima-Njaro, P. Roy. Geogr. Soc., 12, 331-345, 1890.

Meyer, H.: Across East Africa Glaciers, G. Philip and Son, London, 1891.

Meyer, H.: Der Kilimandscharo, Reimer-Vohsen, Berlin, 1900.

Mölg, T. and Hardy, D. R.: Ablation and associated energy balance of a horizontal glacier surface on Kilimanjaro, J. Geophys. Res., 109, D16104, doi:10.1029/2003JD004338, 2004.

Mölg, T. and Kaser, G.: A new approach to resolving climatecryosphere relations: Downscaling climate dynamics to glacierscale mass and energy balance without statistical scale linking, J. Geophys. Res., 116, D16101, doi:10.1029/2011JD015669, 2011.

Mölg, T., Hardy, D. R., and Kaser, G.: Solar-radiation maintained glacier recession on Kilimanjaro drawn from combined ice-radiation geometry modeling, J. Geophys. Res., 108, 4731, doi:10.1029/2003JD003546, 2003.

Mölg, T., Renold, M., Vuille, M., Cullen, N. J., Stocker, T. F., and Kaser, G.: Indian ocean zonal mode activity in a multicentury-integration of a coupled AOGCM consistent with climate proxy data, Geophys. Res. Lett., 33, L18710, doi:10.1029/2006GL026384, 2006.

Mölg, T., Cullen, N. J., Hardy, D. R., Kaser, G., and Klok, L.: Mass balance of a slope glacier on Kilimanjaro and its sensitivity to climate, Int. J. Climatol., 28, 881-892, doi:10.1002/joc.1589, 2008a.

Mölg, T., Hardy, D. R., Cullen, N. J., and Kaser, G.: Tropical glaciers, climate change, and society: Focus on Kilimanjaro (East Africa), in: The Darkening Peaks: Glacial Retreat in Scientific and Social Context, edited by: Orlove, B., Wiegandt, E., and Luckman, B., University of California Press, Berkeley, London, 168-182, 2008b.

Mölg, T., Chiang, J. H. C., Gohm, A., and Cullen, N. J.: Temporal precipitation variability versus altitude on a tropical high mountain: Observations and mesoscale atmospheric modeling, Q. J. Roy. Meteorol. Soc., 135, 1439-1455, doi:10.1002/qj.461, 2009a.
Mölg, T., Cullen, N. J., Hardy, D. R., Winkler, M., and Kaser, G.: Quantifying climate change in the tropical mid-troposphere over East Africa from glacier shrinkage on Kilimanjaro, J. Clim., 22, 4162-4181, doi:10.1175/2009JCLI2954.1, 2009b.

Mölg, T., Grosshauser, M., Hemp, A., Hofer, M., and Marzeion, B.: Limited forcing of glacier loss through land cover change on Kilimanjaro, Nat. Clim. Change, 2, 254-258, doi:10.1038/nclimate1390, 2012.

Nilsson, E.: Quaternary glaciations and pluvial lakes in British East Africa, Geogr. Ann., 13, 249-349, 1931.

Osmaston, H.: Glaciers, glaciations and equilibrium line altitudes on Kilimanjaro, in: Quarternary and environmental research on East African mountains, edited by: Mahaney, W. C., Balkema, Rotterdam, 7-30, 1989.

Racoviteanu, A. E., Paul, F., Raup, B., Khalsa, S. J. S., and Armstrong, R.: Challenges and recommendations in mapping of glacier parameters from space: results of the 2008 Global Land Ice Measurements from Space (GLIMS) workshop, Boulder, Colorado, USA, Ann. Glaciol., 50, 53-69, 2009.

Salt, G.: The Shira Plateau of Kilimanjaro, Geogr. J., 117, 150-164, 1951.

Sampson, D. N.: The geology, volcanology and glaciology of Kilimanjaro, in: Guide Book to Mount Kenya and Kilimanjaro, edited by: Mitchell, J., The Mountain Club of Kenya, Nairobi, Kenya, 155-171, 1971.

Thompson, L. G., Mosley-Thompson, E., Davis, M. E., Henderson, K. A., Brecher, H. H., Zagorodnov, V. S., Mashiotta, T. A., Lin, P.-N., Mikhalenko, V. N., Hardy, D. R., and Beer, J.: Kilimanjaro ice core records: evidence of Holocene climate change in tropical Africa, Science, 298, 589-593, 2002.

Thompson, L. G., Brecher, H. H., Mosley-Thompson, E., Hardy, D. R., and Mark, B. G.: Glacier loss on Kilimanjaro continues unabated, P. Natl. Acad. Sci., 106, 19770-19775, 2009.

Uhlig, C.: Vom Kilimandscharo zum Meru, Zeitschrift Ges. Erdkunde Berlin, 627-650, 692-718, 1904.

Winkler, M., Kaser, G., Cullen, N. J., Mölg, T., Hardy, D. R., and Pfeffer, W. T.: Land-based marginal ice cliffs: Focus on Kilimanjaro, Erdkunde, 64, 179-193, doi:10.3112/erdkunde.2010.02.05, 2010. 